\title{
Pressure Changes in Pipe Transporting Mixture of Iraqi Crude Oils (Gathering System)
}

\author{
Maha R. Abdul-Ameer \& Mohammed M. Daway \\ University of Baghdad, Petroleum Engineering Department
}

\section{Abstract:}

A study has been done to represent the pressure changes along gathering system in pipelines transporting Iraqi's crude oils; the study is divided into four parts. The first part represents the calculations of pressure drop in pipelines transporting petroleum fluid from the well head to a gathering point. In this part, there is a two-phase flow (gas and liquid). The calculations of pressure change in this part depends upon determination of some properties such as liquid and gas density, liquid and gas viscosity, liquid hold up and friction factor.

Determining the liquid hold up and then pressure drop are achieved using two methods, the first method is modified Beggs and Brill correlation, depending on three assumed flow patterns. The second is Aziz et al. correlation, depending on three flow patterns also but are different to that of modified Beggs and Brill. While a method of Colebrook used in determination of two-phase friction factor. The results of two-phase flow calculations show that modified Beggs and Brill correlation (having error of $0.26 \%$ ) better than Aziz et al. correlation (having error of $0.55 \%$ ).

In the second part there are calculations of pressure change in liquid flow in a pipeline from the gathering point to the first stage of separators. In this part Colebrook correlation is used to determine the friction factor, Brill and Mukherjee method is used for calculation of pressure change.

Mukherjee and Brill method gave good results with respect to the pressure drop of flow in the axial pipeline after the gathering point of the actual field data. The third part deals with the networking in pipelines, types of gathering 
systems presented and discussed, the calculations of pressure change in a simple gathering system is studied. The fourth part discusses optimization techniques; Constrained Rosenbrock is used to find optimum pressure which gives favorable oil properties. They have been achieved with some assumptions; they are:

1. Minimum Produced gas oil ratio.

2. Minimum formation volume factor.

3. Maximum API gravity.

\section{Introduction:}

\section{A. Pipeline Flow Correlations}

The prediction of pressure drop during two-phase, gas-liquid flow in horizontal or semi-horizontal pipes is of great significance to petroleum industry. Extensive theoretical and experimental research has been conducted on horizontal, and inclined multi-phase flow. Most published pressure loss prediction correlations require prediction of three parameters:

1. The liquid hold up.

2. Two-phase friction factor.

3. Flow pattern.

However, many investigators of multiphase flow chose to separate their experimental data into groups that fit the various flow patterns or regimes. 


\section{B. Network Pipelines and Gathering Systems}

Multiphase flow in gathering systems is of considerable interest to petroleum engineering as well as many working in other branches of Engineering. Petroleum Engineers are particularly interested in the prediction of flow pattern, hold up and pressure drop in well tubing and gathering flow lines or networks.

These calculations are usually rather involved and the problem is further complicated because:

1. No single design method is "the best" under all conditions,

2. Several design methods must be tried to get some appreciation for the possible range of answers, and

3. Where reliable fluid property or other data are not available, sensitivity of results to variations of these data must be investigated.

This made hand calculations impractical. The calculations are, however, particularly amenable to computer programs.

\section{Statement of the Problem}

The calculations related to gathering system (from the well head to a gathering point and then to the first stage of separators) are very complex and very difficult to solve with hand calculations.

Many studies appeared to describe the calculation of gathering systems, but there is no any study represents the total calculations of gathering systems from the wells to the separator.

In this study a computer program is developed to perform all the complete calculations of the gathering system. The program gave the results in a short time with a high accuracy. 


\section{Modeling of flow:}

\section{A. Single-phase flow}

The pressure gradient is made of three components. Thus[1]:

$$
\left(\frac{d p}{d L}\right)_{t}=\left(\frac{d p}{d L}\right)_{f}+\left(\frac{d p}{d L}\right)_{e l}+\left(\frac{d p}{d L}\right)_{\text {acc }}
$$

Whelle; two computer programs are developed. Each program performs all the calculations of the four parts. The first program is developed using FC $\left(\frac{d p}{d L}\right)$ Adtalprgasgree gkadlenthe second is developed using Visual Basic lanomage.

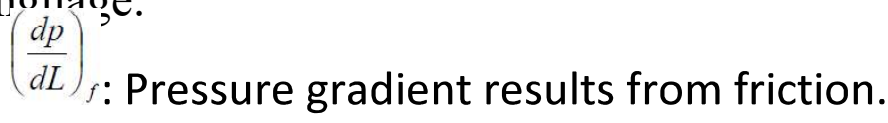

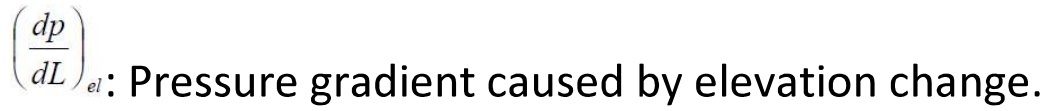

$\left(\frac{d p}{d L}\right)_{\text {acc }}$ : Pressure gradient results from change in velocity.

The three parameters (pressure gradient) is defined as[2]:

$$
\begin{aligned}
& \left(\frac{d p}{d L}\right)_{f}=\frac{f \rho v^{2}}{2 g_{c} d} \\
& \left(\frac{d p}{d L}\right)_{e l}=\rho \frac{g}{g_{c}} \sin \theta{ }^{\prime} \\
& \left(\frac{d p}{d L}\right)_{a c c}=\frac{\rho v d v}{g_{c} d Z}
\end{aligned}
$$




\section{B. Hydraulics of Pipelines}

In this section, there is some of the major flow equations used for Hydraulic calculations in pipeline transportation of liquids. Determination of friction factor is studied using formulas of last studies.

\section{Liquids flow in pipelines:}

In order to study the liquid flow in pipelines, the types of liquid flow in pipelines must be studied and presented. Determination the type of flow is depending on Reynold's number [3].

$$
\begin{aligned}
& \operatorname{Re}=\frac{1488 \rho u d}{\mu} \\
& u=\frac{Q}{A_{P}} \\
& A_{P}=\frac{\pi}{4}\left(\frac{d^{2}}{144}\right)
\end{aligned}
$$

There are two basic types of liquid flow; laminar and turbulent. Where:

$\operatorname{Re} \leq 2000$; Laminar flow,

$2000<\operatorname{Re} \leq 4000 ;$ Transition flow,

$\operatorname{Re}>4000$; Turbulent flow. 


\section{Friction Factor for Single-Phase Flow:}

Calculation of frictional losses requires the determination of values for friction factors, the procedure first requires an evaluation of whether the flow is laminar or turbulent.

\section{Moody Friction Factor:}

Moody ${ }^{(4)}$ studied the friction factor for Newtonian fluid flow. He presented some correlations to calculate the friction factor as follows:

\section{A- For Laminar Flow}

For laminar flow, the friction factor may be calculated from Moody equation[4]:

$$
f=\frac{64}{\operatorname{Re}}
$$

\section{B- For Turbulent Flow}

Colebrook[5] proposed an empirical equation to describe the variation of friction factor in the turbulent flow region. It has become the basis for modern friction factor charts:

$$
\frac{1}{\sqrt{f}}=1.74-2 \log \left(\frac{2 \varepsilon}{d}+\frac{18.7}{\operatorname{Re} \sqrt{f}}\right)
$$

Moody [4] prepare a monograph figure (1) that shows the variations of friction factors with Reynold's number and relative roughness. 


\section{Two-Phase Flow in Pipelines:}

When two or more phases flow simultaneously in pipes, the flow behavior is much more complex than for single-phase flow. The phases tend to separate because of difference in density. Shear stresses at the pipe wall are different for each phase as a result of their different densities and viscosities. Expansion of the highly compressible gas phase with decreasing pressure increases the in-situ volumetric flow rate of the gas. As a result, the gas and liquid phases normally do not travel at the same velocity than the liquid phase, causing a phenomenon known as slippage[1]. Perhaps the most distinguishing aspect of multi-phase flow is the variation in the physical distribution of the phases in the flow conduit, a characteristic known as flow pattern or flow regime. During multiphase flow through pipes, the flow pattern that exists depends on the relative magnitudes of the forces that act on the fluids[1].

\section{Flow patterns:}

Predicting the flow patterns that occurs at a given location in a pipeline is extremely important. The empirical correlation or mechanistic model used to predict flow behavior varies with flow pattern. Beggs and Brill [6] summarized numerous investigations that have described flow patterns in pipes and that made attempts to predict when they occur. Essentially all flow pattern predictions are based on data from low-pressure systems, with negligible mass transfer between the phases and with a single liquid phase[1].

As shown in figure (2), in bubble flow, free gas is present as a bubble in a continuous liquid phase. At the other extreme is mist flow in which the gas phase is continuous and liquid droplets are entrained in the gas. Between these 
two extremes are other types of flow, including stratified, wavy and slug flow. In slug flow at low flow rates liquid can occupy the entire cross section of the pipeline at points in the line. This is likely to occur at uphill portions of the pipeline. This type of flow can produce liquid slugs that exit the pipeline intermittently. Because of this, it is often necessary to include equipment to catch these slugs of liquid at the end of the pipeline to prevent damage to processing or other facilities.

\section{Flow regime:}

Almost invariably, the gas and liquid phases travel through a pipe at different velocities[7]. This gives a rise to a liquid hold up effect, because the fraction of the pipe volume occupied by the liquid phase under flowing conditions will be significantly different from the volume fraction of the liquid in the two-phase mixture entering the pipe. The total pressure losses for a two-phase mixture generally include a hydrostatic head contribution, which is calculated using a mixture density. The correlation used to calculate liquid hold up is the modified Beggs and Brill method[8][6].

In this method the flow regime in horizontal pipes is divided into four patterns, and for each pattern of flow an empirical equation is proposed. The flow pattern prevail in the pipe line section is determined by computing Froud number $\left(\mathrm{N}_{\mathrm{FR}}\right)$ and four dimensionless parameters (L1, L2, L3, L4) which are function of the no-slip liquid hold up $\left(\psi_{\mathrm{N}}\right)$.

$$
\begin{gathered}
\psi_{N}=\frac{V_{s l}}{V_{m}} \\
N_{F R}=\frac{V_{m}^{2}}{g d}
\end{gathered}
$$


$L 1=316 \psi_{N}^{0.302}$

$L 2=.000925 \psi_{N}^{-2.468}$

$L 3=0.1 \psi_{N}^{-1.452}$

$L 4=0.5 \psi_{N}^{-6.738}$

$N_{L V}=1.938 V_{s l}\left(\frac{\rho_{l}}{\sigma}\right)^{0.25}$

The limit of the horizontal flow regimes as defined by the modified Beggs and Brill are as follows:

1- Segregated flow:

$\psi_{\mathrm{N}}<0.01$ and $\mathrm{N}_{\mathrm{FR}}<\mathrm{L} 1$ or $\psi_{\mathrm{N}} \geq 0.01$ and $\mathrm{N}_{\mathrm{FR}}<\mathrm{L} 2$

The slip liquid hold up is calculated as follows:

$$
\psi_{s}=\frac{0.98 \psi_{N}^{0.4846}}{N_{F R}^{0.0868}}
$$

2- Intermittent flow:

$0.01 \leq \psi_{\mathrm{N}}<0.4$ and $\mathrm{L} 3<\mathrm{N}_{\mathrm{FR}} \leq \mathrm{L} 1$ or $\psi_{\mathrm{N}} \geq 0.4$ and $\mathrm{L} 3<\mathrm{N}_{\mathrm{FR}} \leq \mathrm{L} 4$

The slip liquid hold up is calculated as follows:

$$
\psi_{S}=\frac{0.845 \psi_{N}^{0.5351}}{N_{F R}^{0.0173}}
$$


3- Disturbed flow:

$\psi_{\mathrm{N}}<0.4$ and $\mathrm{N}_{\mathrm{FR}} \geq \mathrm{L} 1$ or $\psi_{\mathrm{N}} \geq 0.4$ and $\mathrm{N}_{\mathrm{FR}}>\mathrm{L} 4$

The slip liquid hold up is calculated as follows:

$\psi_{S}=\frac{1.065 \psi_{N}^{0.5824}}{N_{F R}^{0.0609}}$

4- Transition flow:

$\psi_{\mathrm{N}} \geq 0.01$ and $\mathrm{L} 2 \leq \mathrm{NFR} \leq \mathrm{L} 3$

When the flow fall in the transition region, the slip liquid hold up must be calculated using both segregated and intermittent equations and interpolating using the following weighting factors:

$$
\begin{aligned}
& \psi_{S(\text { Transition })}=A \psi_{S(\text { Segregated })}+(1-A) \psi_{S(\text { Intermitent })} \\
& A=\frac{L 3-N_{F R}}{L 3-L 2}
\end{aligned}
$$

\section{Total Pressure Losses in Multi-Phase Flow:}

\section{Modified Beggs and Brill Method}

The pressure gradient equation for single phase can be modified for multiphase flow by considering the fluids to be homogeneous mixture. Thus: 


$$
\frac{d p}{d L}=\frac{f \rho v^{2}}{2 d}+\rho g \sin \theta+\rho v \frac{d v}{d L}
$$

Where the definition for $\rho$ and $v$ can vary with different investigators [1].

Equation (22) shows that the total pressure drop for a two phase flow pipeline is the sum of the pressure losses due to:

1- Fluid friction effects,

2- Hydrostatic head effects, and

3- Kinetic energy or acceleration effects.

Thus:

$\Delta P_{t}=\Delta P_{f}+\Delta P_{E}+\Delta P_{K E}$

where: $\Delta P_{t} \quad$ : total pressure drop.

$\Delta P_{f}:$ pressure drop due to friction.

$\Delta P_{E}:$ pressure drop due to elevation.

$\Delta P_{K E} \quad$ : pressure drop due to kinetic energy effects.

The pressure loss due to fluid friction is calculated according to Beggs and Brill method, by the following expression[9]:

$$
\Delta P_{f}=\frac{f_{t p} \rho_{n} L u_{m}^{2}}{2 d g_{c}}
$$


The two phase friction factor, $f_{t p}$, had been defined by Beggs and Brill as an empirical ratio multiplied by a no slip friction factor as follows[8]:

$$
f_{p p}=R_{f} \times f_{n s}
$$

$f_{n s}=\frac{1.325}{\left[\ln \left(\frac{\varepsilon}{3.7 d}+\frac{5.74}{R_{e n}{ }^{0.9}}\right)\right]^{2}}$

$R_{e n}=\frac{1488 \rho_{n} u_{m} d}{\mu_{n}}$

where: $R_{\mathrm{en}}$ : no slip Reynold's number, dimensionless.

Beggs and Brill gave the following relation to determine $\left(\mathrm{R}_{\mathrm{f}}\right)(10)$ :

$$
R_{f}=e^{s}
$$

where: s: is an empirical function of (y), and:

$$
\begin{aligned}
& y=\frac{\psi_{N}}{\psi_{S}^{2}} \\
& s=\frac{x s}{-0.0523+3.182 x s+0.8725 x s^{2}+0.01853 x s^{4}} \\
& x s=\ln (y)
\end{aligned}
$$


Pressure drop due to elevation $\left(\Delta P_{E}\right)$ is calculating from the following expression $^{(11)}$ :

$$
\Delta P_{E}=0.2234\left[\rho_{L} E_{f} \Sigma H_{U}-\rho_{g} \Sigma H_{D}\right]
$$

where: $\mathrm{E}_{\mathrm{f}}$ : elevation factor, dimensionless.

$\Sigma H_{U}$ : sum of rises in pipeline profile, $\mathrm{ft}$.

$\Sigma H_{D}$ : sum of falls in pipeline profile, $\mathrm{ft}$.

Flanigan equation[12] is used to calculate the elevation factor:

$$
E_{f}=\frac{1}{1+5.5807 \times V_{s g}^{1.006}}
$$

where: $V_{s g}$ : superficial gas velocity, $\mathrm{ft} / \mathrm{sec}$.

\section{Surface Gathering Systems:}

In most oil and gas production installations, the flow from several wells will be gathered at a central processing station or combined into a common pipeline. Two common types of gathering systems were illustrated by Szilas [13] figure (3).

When individual flow lines all join at a common point, the pressure at the common point is equal for all flow lines. The common point is typically a separator in an oil production system. The following tubing pressure of an individual well $(i)$ is related to the separator pressure by: 


$$
P_{t i}=\Delta P_{f i}+\Delta P_{L i}+\Delta P_{c i}+P_{s e p}
$$

where: $P_{t f i}$ : flowing tuping pressure of well $(i)$, psia.

$P_{\text {sep }}:$ separator pressure, psia.

$\Delta P_{L i}:$ pressure drop through flow line, psia.

$\Delta P_{C i}:$ pressure drop through the choke (if presents), psia.

$\Delta P_{f i}:$ pressure drop through fitting, psia.

In gathering system where individual well are tied into a common pipeline, so that the pipeline flow rate is the sum of the upstream well flow rates as in figure (3), left, each well has a more direct effect on its neighbors. In this type of system, individual well head pressure can be calculated by starting at the separator and working upstream[14].

\section{Pressure Drop through Pipe Fittings:}

When fluids pass through pipe fittings (elbows, tees, etc.) or valves, secondary flows and additional turbulence create pressure drops that must be included to determine the overall pressure drop in a piping network. The effects of valves and fittings are including by adding the equivalent length of the valves and fittings to the actual length of straight pipe when calculating the pressure drop. The equivalent lengths of many standard valves and fittings have been determined experimentally by Crane(14). 


\section{Conduit Laterals Losses:}

If lateral are supplied from a main pipeline figure (4), the discharge of the main line decreases at the lateral by the amount of flow supplied to the lateral [15]. If the main pipe has a constant cross section, the streamline expand at the lateral, as the discharge and velocity are reduced and non-uniform flow results. Hence, the energy equation shows that an increase in pressure head will occur. On the other hand, there are losses along the lateral (due to form resistance and boundary resistance) which will cause a decrease in pressure head. These two conditions which cause a change in head tend to counteract each other so that under some conditions the net change in head will be an increase, and under other conditions the head will decrease in the direction of flow.

If the boundary resistance is negligible, the head loss can be written as follows:

$$
h_{L}=C_{L} \frac{\left(V_{1}-V_{2}\right)^{2}}{2 g}
$$

where: $h_{L}$ : head loss.

$$
C_{L}: \text { loss coefficient. }
$$

\section{Field Data:}

A simple gathering system data from Jamboor Field (north of Iraq) is used in this work, the first part of the data are presented in Table (2). These data deal with the flow parameters in pipelines from twelve producing wells to a gathering point. Figure (5) represents a simplest (ideal) scheme of pipelines and gathering point for simple gathering system.

The second part of data deals with flow of resulting fluid in the axial pipeline showed in figure (5) from the gathering point to the separator. 


\section{Computer Program:}

In order to analyze a gathering system, two computer programs are developed to analyze the total calculation of gathering system from the wells to the separator. The first is developed using FORTRAN language, while the second is developed using Visual Basic language. Every one of them gives complete results of gathering system, so the user can use anyone of the two programs to get the results.

\section{a. Computer Program Using FORTRAN Language}

Every component of the gathering system is programmed individually and then linked together in order to determine the pressure losses in every component. The computer program consists of a main program which linked with some subprograms. In the beginning the program reads the input data from a data file then is linked with a subprogram analyzes the calculation of the flow of multi-phase in pipelines from the wells to the gathering point. After that the main program is linked with another subprogram to calculate the pressure drop in the axial pipeline from the gathering point to the separator.

To calculate the optimum pressure which gave minimum GOR, minimum Bo and maximum API; the main program is finally connected with a subprogram to analyze the optimization technique calculations.

After running the program, the results can be seen in some files with the program.

\section{b. Computer Program Using Visual Basic Language}

This program is similar to FORTRAN program in most steps and properties, the main difference between the FORTRAN program and this program is that 
the first program contains some subprograms, while this program doesn't contain any subprogram. This program is simple to use, when the user run the program a form is appeared. The user can press Run button, Then some changes are happened to the form, Exit button is appeared instead of Run button and the value of average absolute percentage error is appeared too. When the user press exit button he can see the results, the results are saved in some files with the program.

\section{Results and Discussion:}

\section{Two-Phase Results}

Two methods have been used to calculate the pressure in two-phase flow in pipelines presented: Modified Beggs and Brill method [6] and Aziz et al. Method[1]. Calculated pressures for the twelve pipelines using the two methods are presented in Table (5). In this table there is also values of absolute percentage error (AAPE) calculated from:

$A A P E=\frac{1}{n}\left|\frac{P_{c}-P_{m}}{P_{m}}\right| \times 100 \%$

where: Pc: calculated pressure (psia).

$$
\begin{aligned}
& \text { Pm : measured pressure (psia). } \\
& n \quad: \text { no. of the wells. }
\end{aligned}
$$

Figure (6) shows the comparison between the results of the two methods. 


\section{Effect of Some Parameters on the Pressure Drops:}

\section{A. Effect of Liquid Flow Rate}

The effect of flow rate is studied and presented in Table (4) and figures (7\& 8). These (table and figures) showed that the liquid flow rate has a significant effect on the pressure results, when the flow rate increase the pressure drop is also increased and then the resulting pressure is decreased.

\section{B. Effect of Oil Specific Gravity}

The effect of oil specific gravity studied and presented in Table (5) and figures $(9 \& 10)$. There are results of original specific gravity and specific gravity plus $\backslash$ minus (0.1). It is found that the specific gravity of oil varies directly with the pressure drop, i.e. the pressure drop increases when the specific gravity increases, and decreases when the specific gravity decreases.

\section{Effect of oil formation volume factor}

Table (6) and figures $(11 \& 12)$ showed that the change of oil formation volume factor has greatly effect on the pressure results. The increasing in the oil formation volume factors of $(0.1 \mathrm{bbl} / \mathrm{STB})$ causes an increase in pressure drop of about ( 3 psi), i.e. oil formation volume factor varies directly with the pressure drop.

\section{Effect of Gas Formation Volume Factor}

Table (7) and figures (13\& 14) showed that the change of gas formation volume factor has a significant effect on the pressure results. The increasing in the gas formation volume factors of $\left(0.001 \mathrm{ft}^{3} / \mathrm{SCF}\right)$ causes an increase in pressure drop of about (1.2-2 psi), i.e. gas formation volume factor varies directly with the pressure drop. 


\section{E. Effect of oil Viscosity}

Table (8) and figures (15) and (16) showed that the change of oil viscosity has a significant effect on the pressure results. The increasing in oil viscosity of $(0.1 \mathrm{cp})$ causes an increase in pressure drop of about (2 psi), i.e. oil viscosity varies directly with the pressure drop.

\section{F. Effect of Gas Viscosity}

Table (9) and figures (17\& 18) showed that the change of gas viscosity has no significant effect on the pressure results. The increasing in oil viscosity of $(0.001 \mathrm{cp})$ causes an increase in pressure drop of about (.01 psi), i.e. change of gas viscosity has a very little effect on pressure drop.

\section{G. Effect of Produced Gas-Oil Ratio}

Table (10) and figures (19 \& 20) showed that the change of gas-oil ratio has a significant effect on the pressure results. The increasing in gas-oil ratio of (100 $\mathrm{SCF} / \mathrm{STB}$ ) causes an increase in pressure drop of about (2 psi), i.e. change of gas viscosity has a very little effect on pressure drop.

\section{Results of Flow in the Axial Pipeline:}

The flow in the axial pipeline is two-phase (gas and liquid), but the two methods (modified Beggs and Brill method and Aziz et al. method) failed to give an accurate results in this section, so a method of single phase flow (Brill and Mukherjee) is used to calculate the pressure changes in this section and it gave good results with respect to field data.

Table (13) shows the output data of computer program for assuming different inlet pressures with the program results of oil formation volume factor, solution gas-oil ratio and separator pressure. From the optimization technique, 
calculation of optimum pressure depends upon two objective functions, the first is to minimize the oil formation volume factor, and the second is to minimize the solution gas-oil ratio.

\section{A. Effect of Pressure Changes on the Oil Formation Volume Factor}

Figure (21) shows the effect of pressure changes on the oil formation volume factor in single-phase flow, it is clearly that the pressure is varies directly with the oil formation volume factor.

\section{B. Effect of Pressure Changes on the Solution Gas-Oil Ratio}

Figure (22) shows the effect of the pressure change on the solution gas-oil ratio in single-phase flow, the figure shows that when the pressure is increased then the solution gas-oil ratio is increased (i.e. the pressure change varies directly with the solution gas-oil ratio).

\section{Effect of Pressure Changes on the Oil Viscosity}

Figure (23) shows the effect of the pressure change on the oil viscosity in single-phase flow. In this figure, it is clearly that the pressure varies inversely with the oil viscosity.

\section{Effect of Pressure Changes on the API}

Figure (24) shows the effect of the pressure change on the API in singlephase flow. The figure shows that the pressure varies inversely with the API gravity. 


\section{Conclusions:}

1. The sensitivity of the pressure results in two-phase flow is widely dependent upon some parameters such as; oil density, oil and gas formation volume factor, pipeline size and length, oil viscosity and gas-oil ratio. While other parameters have minor effect on the pressure results such as; gas density, gas viscosity and liquid surface tension.

2. Two methods are used to calculate the pressure drop of the two-phase flow in pipelines; they are modified Beggs and Brill method and Aziz et al. method. Both of the two methods gave good results. Modified Beggs and Brill method gave an AAPE of (0.26\%), while Aziz et al. method gave an AAPE equal to $(0.55 \%)$.

3. For the flow in the axial pipeline, it is found that the pressure of gathering point varies directly with the oil formation volume factor and solution gas oil ratio, and inversely with the oil viscosity and API.

4. Mukherjee and Brill method gave good results with respect to the pressure drop of flow in the axial pipeline after the gathering point of the actual field data. 


\section{Nomenclature:}

\section{English Symbols}

\begin{tabular}{|c|l|c|}
\hline Symbol & Definition & Unit \\
\hline $\mathrm{A}_{\mathrm{P}}$ & Cross sectional area of pipeline. & $\mathrm{ft}^{2}$ \\
\hline $\mathrm{API}$ & American Petroleum Institute gravity. & $\mathrm{API}$ \\
\hline $\mathrm{B}_{\mathrm{o}}$ & Oil formation volume factor. & $\mathrm{bbl} / \mathrm{STB}$ \\
\hline $\mathrm{B}_{\mathrm{g}}$ & Gas formation volume factor. & $\mathrm{ft}^{3} / \mathrm{SCF}$ \\
\hline $\mathrm{C}_{\mathrm{o}}$ & Oil compressibility. & $\mathrm{psia}^{-1}$ \\
\hline $\mathrm{d}$ & Inside diameter of pipeline. & $\mathrm{in}$ \\
\hline $\mathrm{du} / \mathrm{dy}$ & Shear rate. & $\mathrm{sec}^{-1}$ \\
\hline$f_{\mathrm{tp}}$ & Two phase friction factor. & $\mathrm{dimensionless}^{-1}$ \\
\hline $\mathrm{g}$ & Gravitational constant. & $\mathrm{Ft} / \mathrm{sec}^{2}$ \\
\hline $\mathrm{g}_{\mathrm{c}}$ & Conversion factor, $(=32.174)$. & $\mathrm{lbf.ft} / \mathrm{lbm.sec}$ \\
\hline $\mathrm{L}$ & Pipeline section length. & $\mathrm{ft}$ \\
\hline $\mathrm{N}_{\mathrm{FR}}$ & Froud Number. & $\mathrm{dimensionless}^{2}$ \\
\hline $\mathrm{N}_{\mathrm{LV}}$ & Liquid Velocity number. & $\mathrm{dimensionless}$ \\
\hline $\mathrm{P}$ & Pressure. & $\mathrm{Psia}$ \\
\hline $\mathrm{Q}$ & Liquid flow rate. & $\mathrm{ft} / \mathrm{sec}$ \\
\hline $\mathrm{R}_{\mathrm{e}}$ & Reynold's number. & $\mathrm{dimensionless}$ \\
\hline $\mathrm{R}_{\mathrm{S}}$ & Solution gas oil ratio. & $\mathrm{SCF} / \mathrm{STB}$ \\
\hline $\mathrm{T}$ & Temperature. & ${ }^{\circ} \mathrm{F}$ \\
\hline$u$ & Velocity. & $\mathrm{ft} / \mathrm{sec}$ \\
\hline
\end{tabular}

\section{Greek Symbols:}

\begin{tabular}{|c|l|c|}
\hline Symbol & Definition & Unit \\
\hline$\gamma$ & Oil specific gravity. & dimensionless \\
\hline$\gamma_{g 100}$ & Gas specific gravity at (100 psia). & dimensionless \\
\hline$\rho$ & Density. & $\mathrm{lbm} / \mathrm{ft}^{3}$ \\
\hline$\mu$ & Viscosity. & $\mathrm{cp}$ \\
\hline$\psi s$ & Liquid hold up. & dimensionless \\
\hline$\Delta \mathrm{P}$ & Pressure drop. & $\mathrm{psia}$ \\
\hline$\varepsilon$ & Roughness of pipe. & $\mathrm{in}$. \\
\hline$v$ & kinematic viscosity & $\mathrm{ft}^{2} / \mathrm{sec}$ \\
\hline
\end{tabular}

\section{Subscript:}

\begin{tabular}{|c|l|}
\hline Symbol & $\begin{array}{l}\text { Definitio } \\
\text { n }\end{array}$ \\
\hline tp & two-phase. \\
\hline o & oil. \\
\hline 1 & liquid. \\
\hline $\mathrm{g}$ & gas. \\
\hline $\mathrm{ns}$ & no slip. \\
\hline
\end{tabular}




\section{References}

1. Brill, J.P., and Mukherjee, H., "Multiphase Flow in Wells", SPE Inc., Richardson, Texas, 1999.

2. Abu Al-Soof, N.B., "Multiphase Flow in The Wells of South Rumaila Main Pay", M. Sc. Thesis, University of Baghdad, 1986.

3. King, H.W., and Brater, E., "Handbook of Hydraulics", McGraw-Hill Book co., 5th edition, 1976.

4. Moody, L.f., "Friction Factors for Pipe Flow", Trans., ASME (1944).

5. Colebrook, C.F., "Turbulent Flow in Pipes with Particular Reference to the Transition Region Between the Smooth and Rough Pipe Laws", Journal of institute of civil Engineering, 1939.

6. Beggs, H.D., and Brill J.P., "A study of two-phase flow in inclined pipes", JPT, May 1973.

7. Gregory, G.A., and Aziz, K., "Design of Pipeline for Multi-Phase (Gas Condensate) Flow ", JCPT, July-September, 1975.

8. Al-Naaibe, H.J., "Optimization of pipeline transport system", M. Sc. Thesis, University of Baghdad, 2005.

9. Brown, K.E., and Beggs, H.D., "The Technology of Artificial Lift Methods", volume 1, Penn Well books co., Tulsa, Oklahoma, 1977.

10.Gould, T.L., and Ramsey, E.L., "Design of Offshore Gas Pipelines Accounting for Two Phase Flow", JPT, March 1975.

11.Root, J.R., "Natural Gas Flow System: Gathering, Transmission and Storage", a short coarse presented for Iraq national oil co., Baghdad-Iraq, April 1980.

12.Root, J.R., "Natural Gas Flow System: Gathering, Transmission and Storage", a short coarse presented for Iraq national oil co., Baghdad-Iraq, April 1980. 
13.Szilas, A. P., "Production and Transportation of Oil and Gas (Development in Petroleum Science)", Elsevier publishing co., Amsterdam, first edition, 1975.

14.Crane, S.L., "Flow of Fluids through Valves, Fittings and Pipe", JPT, June 1957.

15.Dodge, D.W., and Metzner A.B., "Turbulent Flow of Non-Newtonian Systems", AIChEJ. 1959. 
Table (1) Coefficients for Vazqeuz and Beggs Correlations

\begin{tabular}{|c|c|c|}
\hline Coefficient & API $\leq \mathbf{3 0}$ & API $>\mathbf{3 0}$ \\
\hline $\mathrm{C}_{1}$ & 0.0362 & 0.0178 \\
\hline $\mathrm{C}_{2}$ & 1.0937 & 1.1870 \\
\hline $\mathrm{C}_{3}$ & 25.7245 & 23.931 \\
\hline
\end{tabular}

Table (2) Jamboor Field Measurements Data of a Gathering System

\begin{tabular}{|c|c|c|c|c|c|c|c|c|c|c|c|c|c|c|}
\hline $\begin{array}{c}\text { Well } \\
\text { Head } \\
\text { Pressire } \\
\text { (psia) }\end{array}$ & $\begin{array}{c}\text { Flow } \\
\text { Rate, } \\
\text { STB Day }\end{array}$ & \begin{tabular}{|c|} 
Well \\
Head \\
temp., \\
${ }^{2}$
\end{tabular} & $\begin{array}{c}\text { Chock } \\
\text { Size, } \\
1 / 64 \text { in. }\end{array}$ & $\begin{array}{l}\text { Gas } \\
\text { Specific } \\
\text { Gravity }\end{array}$ & $\begin{array}{l}\text { Liquid } \\
\text { Specific } \\
\text { Gravity }\end{array}$ & $\begin{array}{c}\text { Gas } \\
\text { Viscosity, } \\
\text { cp }\end{array}$ & $\begin{array}{c}\text { Liquid } \\
\text { Viscosity, } \\
\text { Cp }\end{array}$ & $\begin{array}{c}\text { Oil } \\
\text { Formation } \\
\text { Volume } \\
\text { Factor, } \\
\text { bbUSTB } \\
\end{array}$ & $\begin{array}{c}\text { Gas } \\
\text { Formation } \\
\text { Volume } \\
\text { Factor } \\
\text { SCF } / \mathrm{ft}^{3} \\
\end{array}$ & $\begin{array}{l}\text { Diameter } \\
\text { of the pipe, } \\
\text { in. }\end{array}$ & $\begin{array}{c}\text { Pipe } \\
\text { Length, } \\
\mathrm{ft}\end{array}$ & $\begin{array}{l}\text { Produced } \\
\text { GOR, } \\
\text { SCF/STB }\end{array}$ & $\begin{array}{c}\text { Solution } \\
\text { GOR, } \\
\text { SCF } / \text { STB }\end{array}$ & $\begin{array}{c}\text { Upstream } \\
\text { Pressure } \\
\text { of } \\
\text { gathering } \\
\text { point, psia }\end{array}$ \\
\hline 1425 & 3600 & 210 & 42 & 0.795 & 0.8360 & 0.0190 & 0.83363 & 1.137 & 3600 & 6.5 & 22989 & 1245 & 610 & 1395 \\
\hline 1600 & 7300 & 210 & 52 & 0.761 & 0.8303 & 0.0171 & 0.78580 & 1.058 & 7300 & 6.5 & 6555 & 1626 & 875 & 1580 \\
\hline 1530 & 3900 & 210 & 52 & 0.794 & 0.8950 & 0.0189 & 0.89878 & 1.159 & 3900 & 6.0 & 9826 & 1340 & 405 & 1500 \\
\hline 1700 & 4800 & 210 & 48 & 0.771 & 0.8334 & 0.0170 & 0.77627 & 1.178 & 4800 & 6.0 & 24606 & 1378 & 850 & 1635 \\
\hline 1525 & 3600 & 210 & 52 & 0.763 & 0.8517 & 0.0167 & 0.82900 & 1.189 & 3600 & 6.0 & 23622 & 1258 & 465 & 1475 \\
\hline 1650 & 5100 & 210 & 52 & 0.787 & 0.8486 & 0.0173 & 0.79858 & 1.206 & 5100 & 6.5 & 24278 & 1367 & 550 & 1590 \\
\hline 1658 & 8500 & 149 & 52 & 0.774 & 0.8279 & 0.0183 & 0.70998 & 1.297 & 8500 & 6.5 & 16411 & 1083 & 810 & 1590 \\
\hline 1558 & 7400 & 210 & 52 & 0.780 & 0.8483 & 0.0169 & 0.82700 & 1.190 & 7400 & 6.5 & 9842 & 1230 & 490 & 1515 \\
\hline 1400 & 5000 & 210 & 52 & 0.781 & 0.8786 & 0.0180 & 0.83312 & 1.188 & 5000 & 6.5 & 16404 & 1320 & 620 & 1365 \\
\hline 1600 & 6100 & 210 & 52 & 0.808 & 0.8372 & 0.0131 & 0.72878 & 1.081 & 6100 & 6.0 & 8202 & 1554 & 480 & 1550 \\
\hline 1700 & 7000 & 210 & 52 & 0.758 & 0.8538 & 0.0146 & 0.85936 & 1.242 & 7000 & 6.5 & 14764 & 1625 & 645 & 1630 \\
\hline 1250 & 6400 & \begin{tabular}{|l|}
149 \\
\end{tabular} & 48 & 0.766 & 0.8344 & 0.0147 & 0.75743 & 1.196 & 6400 & 6.0 & 9829 & 1200 & 550 & 1200 \\
\hline
\end{tabular}

Table (3) Comparison between measured and calculated pressure

data

\begin{tabular}{|c|c|c|c|c|}
\hline Measured & \multicolumn{2}{|c|}{ Modified Beggs and Brill Method } & \multicolumn{2}{|c|}{ Aziz et al. Method } \\
\hline $\begin{array}{c}\text { Pressure } \\
\text { (psia) }\end{array}$ & $\begin{array}{c}\text { Calculated } \\
\text { Pressure (psia) }\end{array}$ & $\begin{array}{c}\text { Absolute Percentage } \\
\text { Error }\end{array}$ & $\begin{array}{c}\text { Calculated } \\
\text { Pressure (psia) }\end{array}$ & $\begin{array}{c}\text { Absolute Percentage } \\
\text { Error }\end{array}$ \\
\hline 1390 & 1392.06 & 0.14832 & 1395.75 & 0.41337 \\
\hline 1580 & 1577.10 & 0.18308 & 1579.06 & 0.05937 \\
\hline 1500 & 1502.28 & 0.15196 & 1504.47 & 0.29825 \\
\hline 1635 & 1638.24 & 0.19816 & 1646.83 & 0.72370 \\
\hline 1475 & 1482.63 & 0.51744 & 1485.05 & 0.68159 \\
\hline 1590 & 1594.66 & 0.29312 & 1598.56 & 0.53834 \\
\hline 1590 & 1586.99 & 0.18933 & 1603.86 & 0.87170 \\
\hline 1515 & 1517.74 & 0.18075 & 1523.17 & 0.53895 \\
\hline 1365 & 1366.20 & 0.08807 & 1369.44 & 0.32501 \\
\hline 1550 & 1558.84 & 0.57022 & 1559.32 & 0.60132 \\
\hline 1625 & 1628.80 & 0.23369 & 1634.15 & 0.56333 \\
\hline 1200 & 1204.45 & 0.37131 & 1211.14 & 0.92859 \\
\hline & & AAPE $=0.26 \%$ & & A.APE $=0.55 \%$ \\
\hline
\end{tabular}


Table (4) Comparison the Results of Calculated Pressure for Original Flow Rates and Flow Rates \pm 1000 STB/day for All Gathering Pipelines.

\begin{tabular}{|c|c|c|c|c|c|}
\hline \multicolumn{3}{|c|}{ Modified Beggs and Brill Method } & \multicolumn{3}{|c|}{ Aziz et al. Method } \\
\hline $\begin{array}{c}P \text { at Original } \\
Q \text { (psia) }\end{array}$ & $\begin{array}{c}\mathrm{P} \text { at }(\mathrm{Q}+500) \\
\mathrm{STB} / \text { day }(\text { psia })\end{array}$ & $\begin{array}{c}\text { P at }(\mathrm{Q}-500) \\
\text { STB/day (psia) }\end{array}$ & $\begin{array}{c}\text { P at Original } \\
\text { Q (psia) }\end{array}$ & $\begin{array}{c}\mathrm{P} \text { at }(\mathrm{Q}+500) \\
\mathrm{STB} / \text { day (psia) }\end{array}$ & $\begin{array}{c}\text { P at }(Q-500) \\
\text { STB/day (psia) }\end{array}$ \\
\hline 1206.07 & 1199.55 & 1212.16 & 1395.75 & 1380.55 & 1408.13 \\
\hline 1367.39 & 1361.22 & 1373.07 & 1579.06 & 1573.92 & 1583.71 \\
\hline 1401.36 & 1395.11 & 1406.94 & 1504.47 & 1492.34 & 1514.51 \\
\hline 1483.61 & 1472.59 & 1493.41 & 1646.83 & 1626.35 & 1664.34 \\
\hline 1507.65 & 1502.16 & 1512.58 & 1485.05 & 1464.54 & 1501.82 \\
\hline 1517.74 & 1512.61 & 1522.58 & 1598.56 & 1580.26 & 1614.40 \\
\hline 1553.91 & 1546.63 & 1560.66 & 1603.86 & 1592.07 & 1614.60 \\
\hline 1574.09 & 1570.74 & 1577.25 & 1523.17 & 1514.63 & 1530.86 \\
\hline 1597.15 & 1590.48 & 1603.51 & 1369.44 & 1358.29 & 1379.05 \\
\hline 1597.77 & 1588.07 & 1606.71 & 1559.32 & 1547.30 & 1569.95 \\
\hline 1636.29 & 1627.65 & 1644.41 & 1634.15 & 1617.20 & 1649.37 \\
\hline 1638.24 & 1626.06 & 1649.41 & 1211.14 & 1200.02 & 1221.01 \\
\hline
\end{tabular}

Table (5) Comparison the Results of Calculated Pressure for Original specific Gravity and Specific Gravity $\pm \mathbf{0 . 1}$ for All Gathering Pipelines.

\begin{tabular}{|c|c|c|c|c|c|}
\hline \multicolumn{3}{|c|}{ Modified Beggs and Brill Method } & \multicolumn{3}{|c|}{ Aziz et al. Method } \\
\hline $\begin{array}{c}\text { P at Original } \\
\gamma_{\circ} \text { (psia) }\end{array}$ & $\begin{array}{c}\text { P at }\left(\gamma_{0}+.1\right) \\
\text { (psia) }\end{array}$ & $\begin{array}{c}\text { P at }\left(\gamma_{0}-.1\right) \\
(p s i a)\end{array}$ & $\begin{array}{c}\text { P at Original } \\
\gamma_{0} \text { (psia) }\end{array}$ & $\begin{array}{c}\text { P at }\left(\gamma_{0}+.1\right) \\
\text { (psia) }\end{array}$ & $\begin{array}{c}\text { P at }\left(\gamma_{0}-.1\right) \\
\text { (psia) }\end{array}$ \\
\hline 1392.06 & 1388.97 & 1395.21 & 1395.75 & 1392.98 & 1398.57 \\
\hline 1577.10 & 1574.91 & 1579.35 & 1579.06 & 1577.04 & 1581.13 \\
\hline 1502.28 & 1499.83 & 1504.77 & 1504.47 & 1502.20 & 1506.79 \\
\hline 1638.24 & 1632.39 & 1644.21 & 1646.83 & 1641.76 & 1652.01 \\
\hline 1482.63 & 1478.73 & 1486.61 & 1485.05 & 1481.34 & 1488.85 \\
\hline 1594.66 & 1589.51 & 1599.91 & 1598.56 & 1593.72 & 1603.50 \\
\hline 1586.99 & 1580.12 & 1594.00 & 1603.86 & 1598.62 & 1609.21 \\
\hline 1517.74 & 1513.94 & 1521.60 & 1523.17 & 1519.87 & 1526.52 \\
\hline 1366.20 & 1363.16 & 1369.30 & 1369.44 & 1366.67 & 1372.26 \\
\hline 1558.84 & 1554.89 & 1562.84 & 1559.32 & 1555.40 & 1563.32 \\
\hline 1628.80 & 1622.10 & 1635.61 & 1634.15 & 1627.95 & 1640.48 \\
\hline 1204.45 & 1200.07 & 1208.92 & 1211.14 & 1207.41 & 1214.95 \\
\hline
\end{tabular}


Table (6) Comparison the Results of Calculated Pressure for Original oil formation volume factor and oil formation volume factor $\pm \mathbf{0 . 1}$ for All Gathering Pipelines.

\begin{tabular}{|c|c|c|c|c|c|}
\hline \multicolumn{3}{|c|}{ Modified Beggs and Brill Method } & \multicolumn{3}{|c|}{ Aziz et al. Method } \\
\hline $\begin{array}{c}\text { P at Original } \\
\mathrm{B}_{\circ} \text { (psia) }\end{array}$ & $\begin{array}{c}\mathrm{P} \text { at }\left(\mathrm{B}_{\circ}+.1\right) \\
\mathrm{bbl} / \mathrm{STB}(\mathrm{psia})\end{array}$ & $\begin{array}{c}\mathrm{P} \text { at }\left(\mathrm{B}_{\circ}-.1\right) \\
\mathrm{bbl} / \mathrm{STB} \text { (psia) }\end{array}$ & $\begin{array}{c}\mathrm{P} \text { at } \\
\text { Original } \mathrm{B}_{\circ} \text { (psia) }\end{array}$ & $\begin{array}{c}\mathrm{P} \text { at }\left(\mathrm{B}_{\circ}+.1\right) \\
\mathrm{bbl} / \mathrm{STB}(\mathrm{psia})\end{array}$ & $\begin{array}{c}\mathrm{P} \text { at }\left(\mathrm{B}_{\circ}-.1\right) \\
\mathrm{bbl} / \mathrm{STB} \text { (psia) }\end{array}$ \\
\hline 1392.06 & 1388.69 & 1395.30 & 1395.75 & 1393.33 & 1398.07 \\
\hline 1577.10 & 1574.09 & 1579.98 & 1579.06 & 1576.92 & 1581.11 \\
\hline 1502.28 & 1499.43 & 1505.02 & 1504.47 & 1502.44 & 1506.44 \\
\hline 1638.24 & 1630.46 & 1645.64 & 1646.83 & 1641.30 & 1652.11 \\
\hline 1482.63 & 1477.63 & 1487.41 & 1485.05 & 1481.46 & 1488.50 \\
\hline 1594.66 & 1588.24 & 1600.81 & 1598.56 & 1593.96 & 1602.98 \\
\hline 1586.99 & 1577.99 & 1595.51 & 1603.86 & 1597.57 & 1609.83 \\
\hline 1517.74 & 1512.84 & 1522.41 & 1523.17 & 1519.70 & 1526.47 \\
\hline 1366.20 & 1362.10 & 1370.11 & 1369.44 & 1366.51 & 1372.24 \\
\hline 1558.84 & 1553.91 & 1563.57 & 1559.32 & 1555.83 & 1562.68 \\
\hline 1628.80 & 1620.99 & 1636.29 & 1634.15 & 1628.63 & 1639.48 \\
\hline 1204.45 & 1198.90 & 1209.74 & 1211.14 & 1207.24 & 1214.87 \\
\hline
\end{tabular}

Table (7) Comparison the Results of Calculated Pressure for Original gas formation volume factor and gas formation volume factor $\pm \mathbf{0 . 0 0 1}$ for all Gathering Pipelines.

\begin{tabular}{|c|c|c|c|c|c|}
\hline \multicolumn{3}{|c|}{ Modified Beggs and Brill Method } & \multicolumn{3}{|c|}{ Aziz et al. Method } \\
\hline $\begin{array}{c}\text { P at Original } \\
\text { Bg }_{g} \text { (psia) }\end{array}$ & $\begin{array}{l}\mathrm{P} \text { at }\left(\mathrm{B}_{\mathrm{g}}+.001\right) \\
\mathrm{ft}^{3} / \mathrm{SCF} \text { (psia) }\end{array}$ & $\begin{array}{l}\mathrm{P} \text { at }\left(\mathrm{B}_{\mathrm{g}}-.001\right) \\
\mathrm{ft}^{3} / \mathrm{SCF} \text { (psia) }\end{array}$ & \begin{tabular}{|c|} 
P at Original \\
B $_{\mathrm{g}}$ (psia)
\end{tabular} & $\begin{array}{l}\mathrm{P} \text { at }\left(\mathrm{B}_{\mathrm{g}}+.001\right) \\
\mathrm{ft}^{3} / \mathrm{SCF} \text { (psia) }\end{array}$ & $\begin{array}{l}\mathrm{P} \text { at }\left(\mathrm{B}_{\mathrm{g}-} \cdot 001\right) \\
\mathrm{ft}^{3} / \mathrm{SCF} \text { (psia) }\end{array}$ \\
\hline 1392.06 & 1390.82 & 1393.30 & 1395.75 & 1394.12 & 1397.35 \\
\hline 1577.10 & 1575.94 & 1578.27 & 1579.06 & 1577.59 & 1580.51 \\
\hline 1502.28 & 1500.88 & 1503.68 & 1504.47 & 1502.66 & 1506.27 \\
\hline 1638.24 & 1635.86 & 1640.63 & 1646.83 & 1643.92 & 1649.72 \\
\hline 1482.63 & 1480.57 & 1484.70 & 1485.05 & 1482.22 & 1487.85 \\
\hline 1594.66 & 1591.92 & 1597.40 & 1598.56 & 1594.94 & 1602.13 \\
\hline 1586.99 & 1585.29 & 1588.69 & 1603.86 & 1602.11 & 1605.60 \\
\hline 1517.74 & 1515.71 & 1519.77 & 1523.17 & 1520.77 & 1525.53 \\
\hline 1366.20 & 1364.63 & 1367.78 & 1369.44 & 1367.39 & 1371.46 \\
\hline 1558.84 & 1556.52 & 1561.15 & 1559.32 & 1556.21 & 1562.38 \\
\hline 1628.80 & 1625.02 & 1632.57 & 1634.15 & 1629.40 & 1638.83 \\
\hline 1204.45 & 1202.41 & 1206.51 & 1211.14 & 1208.79 & 1213.47 \\
\hline
\end{tabular}


Table (8) Comparison the Results of Calculated Pressure for

Original oil viscosity and oil viscosity $\pm 0.1 \mathrm{cp}$ for all Gathering Pipelines.

\begin{tabular}{|c|c|c|c|c|c|}
\hline \multicolumn{3}{|c|}{ Modified Beggs and Brill Method } & \multicolumn{3}{|c|}{ Aziz et al. Method } \\
\hline $\begin{array}{c}\text { P at Original } \\
\text { Viscosity (psia) }\end{array}$ & $\begin{array}{c}\text { P at }\left(\mu_{0}+.1\right) \\
\text { STB/day (psia) }\end{array}$ & $\begin{array}{c}\text { P at }\left(\mu_{\left.o^{-}-1\right)}\right. \\
\text { STB/day (psia) }\end{array}$ & $\begin{array}{c}\text { P at Original } \\
\text { Viscosity (psia) }\end{array}$ & $\begin{array}{c}\text { P at }\left(\mu_{0}+1\right) \\
\text { STB/day (psia) }\end{array}$ & $\begin{array}{c}\text { P at }\left(\mu_{0}-.1\right) \\
\text { STB/day (psia) }\end{array}$ \\
\hline 1392.06 & 1390.60 & 1393.79 & 1395.75 & 1394.43 & 1397.31 \\
\hline 1577.10 & 1576.11 & 1578.31 & 1579.06 & 1578.13 & 1580.19 \\
\hline 1502.28 & 1501.17 & 1503.58 & 1504.47 & 1503.43 & 1505.70 \\
\hline 1638.24 & 1635.38 & 1641.67 & 1646.83 & 1644.34 & 1649.84 \\
\hline 1482.63 & 1480.77 & 1484.84 & 1485.05 & 1483.26 & 1487.18 \\
\hline 1594.66 & 1592.22 & 1597.58 & 1598.56 & 1596.24 & 1601.34 \\
\hline 1586.99 & 1583.53 & 1591.24 & 1603.86 & 1601.20 & 1607.14 \\
\hline 1517.74 & 1516.05 & 1519.75 & 1523.17 & 1521.68 & 1524.94 \\
\hline 1366.20 & 1364.75 & 1367.93 & 1369.44 & 1368.10 & 1371.03 \\
\hline 1558.84 & 1556.97 & 1561.11 & 1559.32 & 1557.42 & 1561.65 \\
\hline 1628.80 & 1625.96 & 1632.15 & 1634.15 & 1631.48 & 1637.33 \\
\hline 1204.45 & 1202.38 & 1206.97 & 1211.14 & 1209.34 & 1213.33 \\
\hline
\end{tabular}

Table (9) Comparison the Results of Calculated Pressure for Original Gas Viscosity and Gas Viscosity $\pm 0.1 \mathrm{cp}$ for all Gathering Pinelines.

\begin{tabular}{|c|c|c|c|c|c|}
\hline \multicolumn{3}{|c|}{ Modified Beggs and Brill Method } & \multicolumn{3}{|c|}{ Aziz et al. Method } \\
\hline $\begin{array}{c}\text { P at Original } \\
\text { Viscosity (psia) }\end{array}$ & $\begin{array}{c}\text { P at }\left(\mu_{\mathrm{g}}+.001 \mathrm{cp}\right) \\
(\mathrm{psia})\end{array}$ & $\begin{array}{c}\text { P at }\left(\mu_{g} .001\right. \\
\text { cp) (psia) }\end{array}$ & $\begin{array}{c}\text { P at Original } \\
\text { Viscosity (psia) }\end{array}$ & $\begin{array}{c}\text { P at }\left(\mu_{\mathrm{g}}+.001 \mathrm{cp}\right) \\
(\mathrm{p} \text { sia })\end{array}$ & $\begin{array}{c}\text { P at }\left(\mu_{\mathrm{g}}-.001 \mathrm{cp}\right) \\
(\mathrm{p} \text { sia })\end{array}$ \\
\hline 1392.06 & 1392.05 & 1392.07 & 1395.75 & 1395.76 & 1395.74 \\
\hline 1577.10 & 1577.09 & 1577.12 & 1579.06 & 1579.07 & 1579.05 \\
\hline 1502.28 & 1502.27 & 1502.29 & 1504.47 & 1504.48 & 1504.46 \\
\hline 1638.24 & 1638.22 & 1638.26 & 1646.83 & 1646.84 & 1646.82 \\
\hline 1482.63 & 1482.61 & 1482.65 & 1485.05 & 1485.06 & 1485.04 \\
\hline 1594.66 & 1594.63 & 1594.69 & 1598.56 & 1598.57 & 1598.55 \\
\hline 1586.99 & 1586.98 & 1587.00 & 1603.86 & 1603.87 & 1603.85 \\
\hline 1517.74 & 1517.72 & 1517.76 & 1523.17 & 1523.18 & 1523.16 \\
\hline 1366.20 & 1366.19 & 1366.22 & 1369.44 & 1369.45 & 1369.43 \\
\hline 1558.84 & 1558.80 & 1558.88 & 1559.32 & 1559.33 & 1559.31 \\
\hline 1628.80 & 1628.76 & 1628.84 & 1634.15 & 1634.16 & 1634.14 \\
\hline 1204.45 & 1204.44 & 1204.48 & 1211.14 & 1211.15 & 1211.13 \\
\hline
\end{tabular}


Table (10) Comparison the Results of Calculated Pressure for Original Gas-Oil Ratio and Gas-Oil Ratio \pm 100 SCF/STB for All Gathering Pipelines.

\begin{tabular}{|c|c|c|c|c|c|}
\hline \multicolumn{3}{|c|}{ Modified Beggs and Brill Method } & \multicolumn{3}{|c|}{ Aziz et al. Method } \\
\hline $\begin{array}{l}\text { P at Original } \\
\text { GOR (psia) }\end{array}$ & $\begin{array}{l}\text { P at }(\text { GOR }+100) \\
\text { SCF/STB (psia) }\end{array}$ & $\begin{array}{l}\text { P at }(\text { GOR }+100) \\
\text { SCF/STB (psia) }\end{array}$ & $\begin{array}{l}\text { P at Original } \\
\text { GOR (psia) }\end{array}$ & $\begin{array}{l}\text { P at }(\text { GOR }+100) \\
\text { SCF/STB (psia) }\end{array}$ & $\begin{array}{l}\text { P at (GOR+100) } \\
\text { SCF } / \text { STB (psia) }\end{array}$ \\
\hline 1392.06 & 1390.17 & 1393.96 & 1395.75 & 1393.26 & 1398.19 \\
\hline 1577.10 & 1575.67 & 1578.55 & 1579.06 & 1577.24 & 1580.85 \\
\hline 1502.28 & 1500.95 & 1503.61 & 1504.47 & 1502.74 & 1506.18 \\
\hline 1638.24 & 1633.96 & 1642.54 & 1646.83 & 1641.57 & 1652.01 \\
\hline 1482.63 & 1480.29 & 1484.98 & 1485.05 & 1481.84 & 1488.22 \\
\hline 1594.66 & 1591.61 & 1597.72 & 1598.56 & 1594.52 & 1602.54 \\
\hline 1586.99 & 1581.22 & 1592.78 & 1603.86 & 1597.86 & 1609.77 \\
\hline 1517.74 & 1515.46 & 1520.02 & 1523.17 & 1520.47 & 1525.82 \\
\hline 1366.20 & 1364.23 & 1368.19 & 1369.44 & 1366.86 & 1371.97 \\
\hline 1558.84 & 1556.59 & 1561.08 & 1559.32 & 1556.31 & 1562.28 \\
\hline 1628.80 & 1625.10 & 1632.50 & 1634.15 & 1629.50 & 1638.74 \\
\hline 1204.45 & 1201.55 & 1207.36 & 1211.14 & 1207.80 & 1214.44 \\
\hline
\end{tabular}

Table (11) Results of Pressure, Bo and Rs for the Axial Pipeline.

\begin{tabular}{|c|c|c|c|c|c|}
\hline $\begin{array}{l}\text { Pressure } \\
\text { (psia) }\end{array}$ & $\begin{array}{c}\text { Bo } \\
\text { (bbl/STB) }\end{array}$ & $\begin{array}{c}\text { Rs } \\
\text { (SCF/STB) }\end{array}$ & $\begin{array}{c}\text { Separator } \\
\text { Pressure (psia) }\end{array}$ & $\begin{array}{l}\text { Viscosity } \\
\text { of Oil (cp) }\end{array}$ & $\begin{array}{c}\text { API } \\
\text { Gravity }\end{array}$ \\
\hline 625 & 1.139 & 144.930 & 613.591 & 0.680 & 41.277 \\
\hline 650 & 1.142 & 152.847 & 638.592 & 0.668 & 40.988 \\
\hline 675 & 1.146 & 160.863 & 663.593 & 0.657 & 40.699 \\
\hline 700 & 1.150 & 168.975 & 688.594 & 0.647 & 40.413 \\
\hline 725 & 1.154 & 177.180 & 713.595 & 0.636 & 40.128 \\
\hline 750 & 1.158 & 185.476 & 738.596 & 0.626 & 39.846 \\
\hline 775 & 1.162 & 193.860 & 763.597 & 0.617 & 39.565 \\
\hline 800 & 1.166 & 202.331 & 788.598 & 0.607 & 39.287 \\
\hline 825 & 1.171 & 210.885 & 813.599 & 0.598 & 39.011 \\
\hline 850 & 1.175 & 219.523 & 838.599 & 0.590 & 38.738 \\
\hline 875 & 1.179 & 228.241 & 863.600 & 0.581 & 38.467 \\
\hline 900 & 1.184 & 237.037 & 888.601 & 0.573 & 38.199 \\
\hline
\end{tabular}




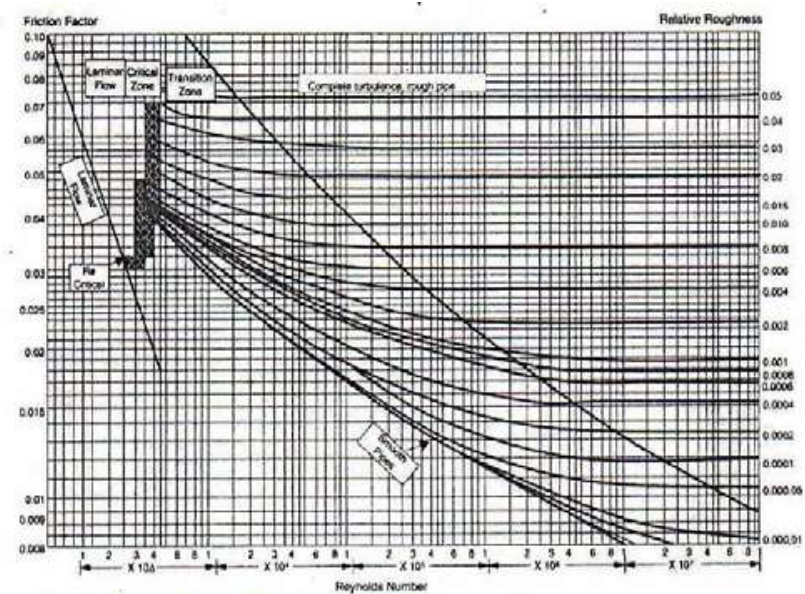

Fig. (1) Moody Diagram Friction

Factor for Flow of Fluids in Pipelines

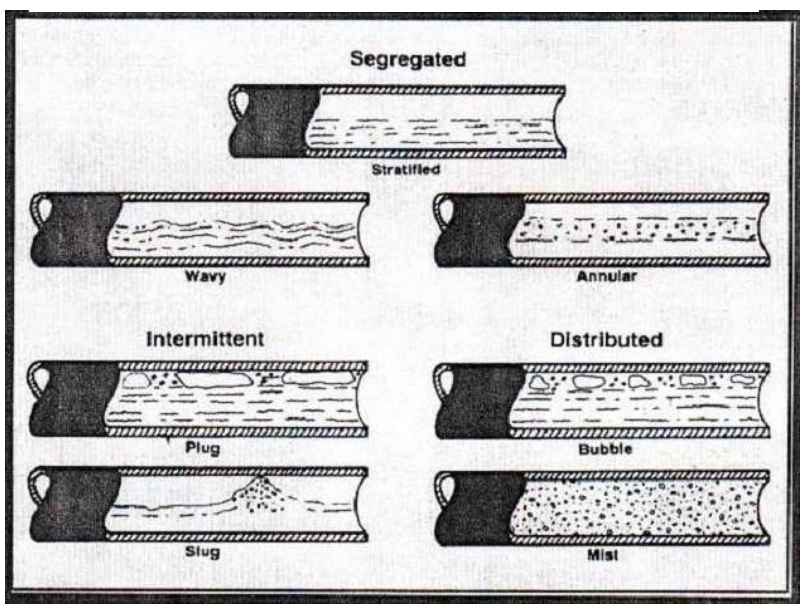

Fig. (2) Flow Regime in Two-Phase Horizontal Pipeline
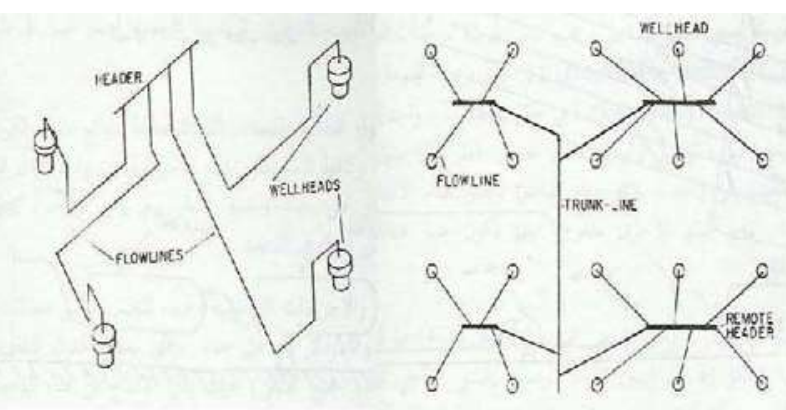

Fig. (3) Oil and Gas Production Gathering System 


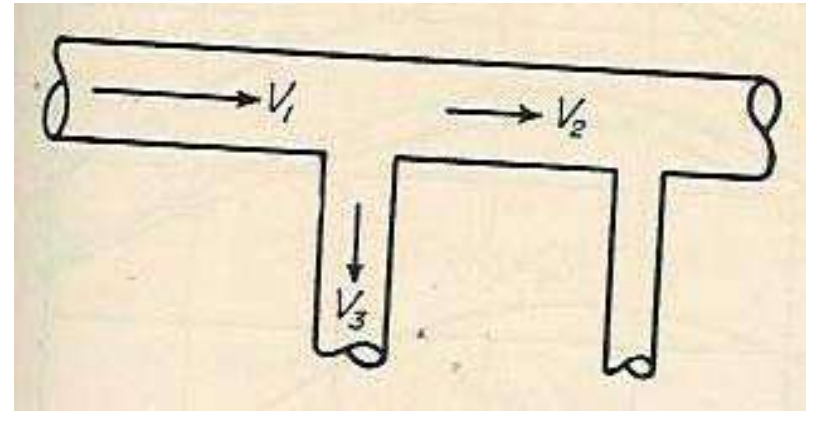

Fig. (4) Conduit Laterals

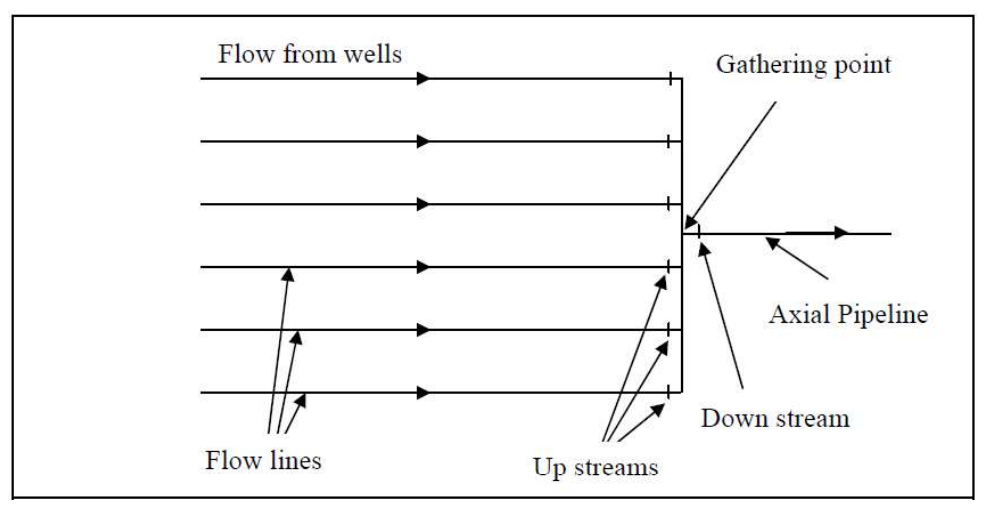

Fig. (5) Simplest Scheme of Simple Gathering

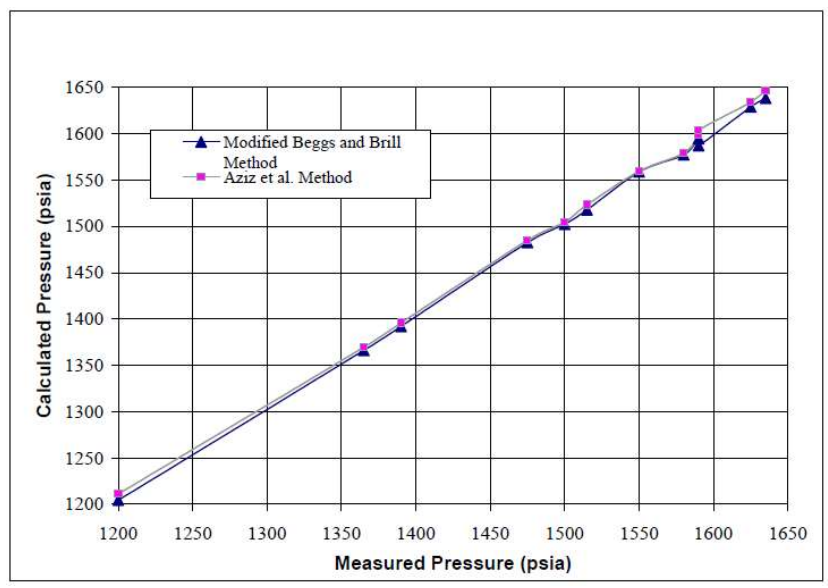

Fig. (6) Comparison between the results of modified Beggs and Brill method and Aziz et al. method 


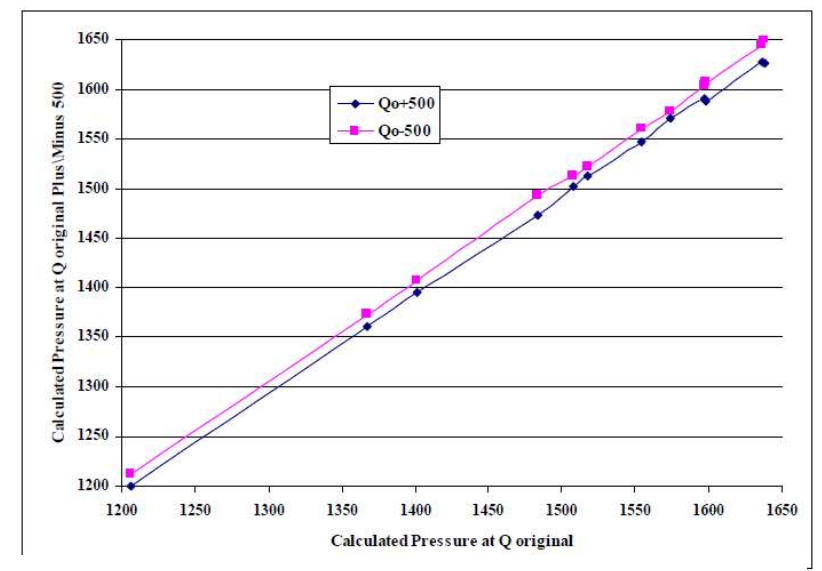

Fig.(7) The Effect of Flow Rate on the Pressure Results Using Modified Beggs

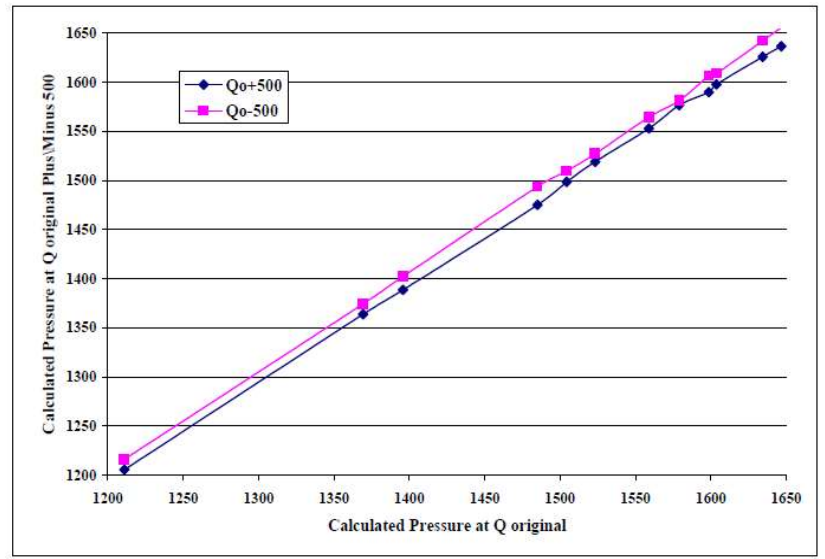

Fig.(8) The Effect of Flow Rate on the Pressure Results Using Aziz et al. Method.

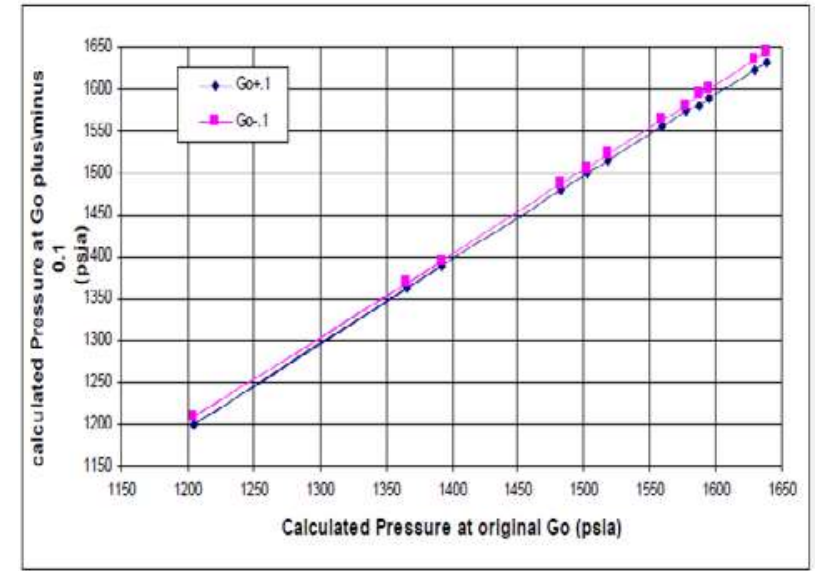

Fig. (9) The effect of specific gravity on the pressure Using Modified Beggs and Brill method. 


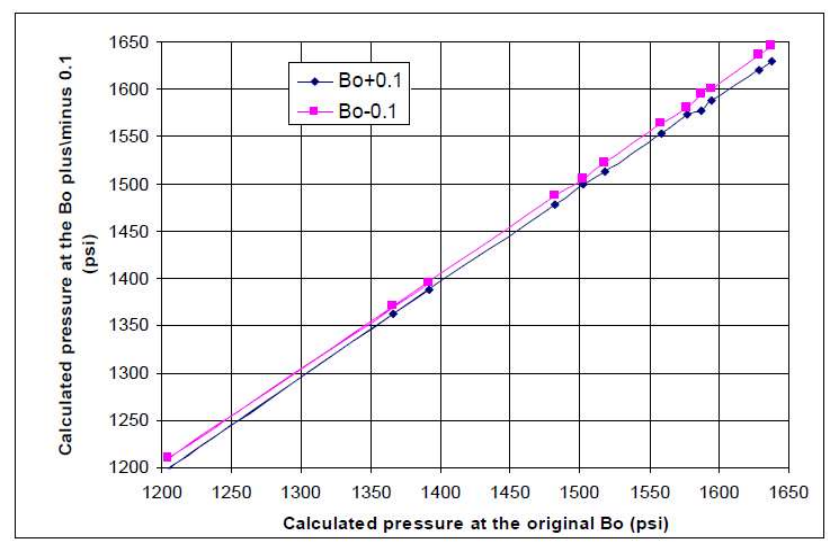

Figure (5-7) Effect of oil formation volume factor on the pressure results using Modified Beggs and Brill Method.

Fig.(11) Effect of oil formation volume factor on the pressure results using Modified Beggs and Brill Method.

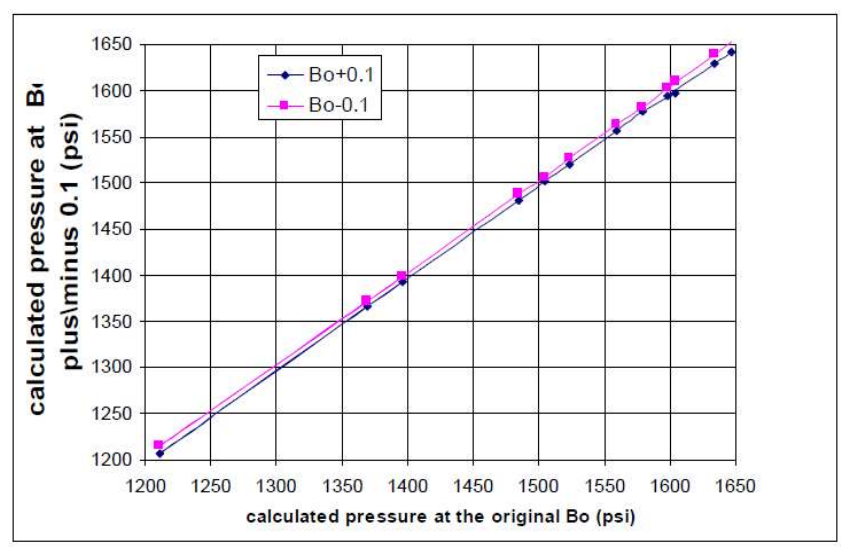

Fig. (12) Effect of oil formation volume factor on the pressure results using Aziz et al. Method.

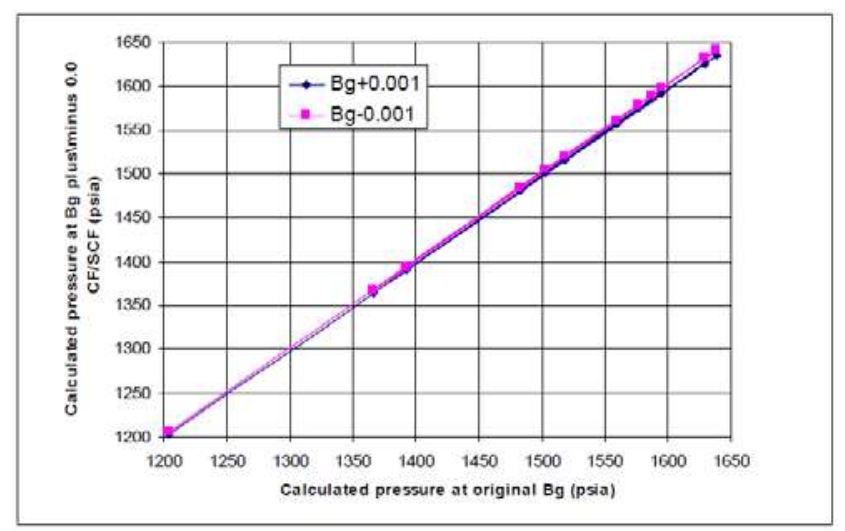

Fig. (13) Effect of gas formation volume factor on the pressure results using Modified Beggs 


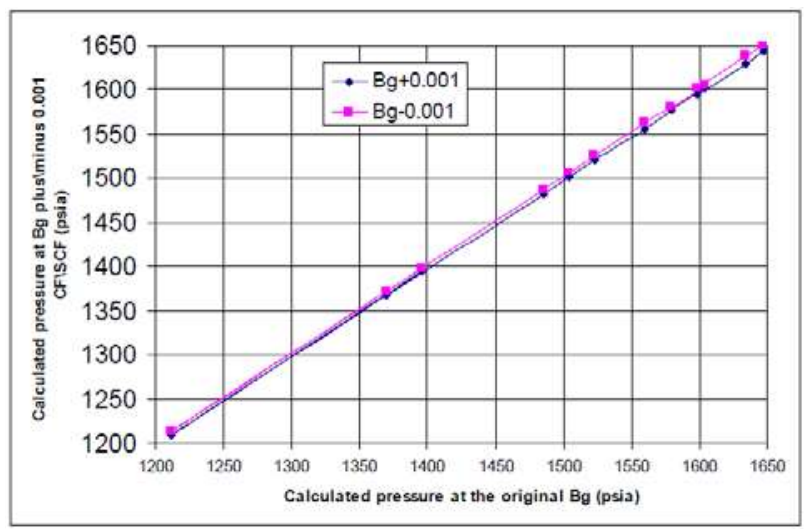

Fig. (14) Effect of gas formation volume factor on the pressure results using Aziz et al.

Method.

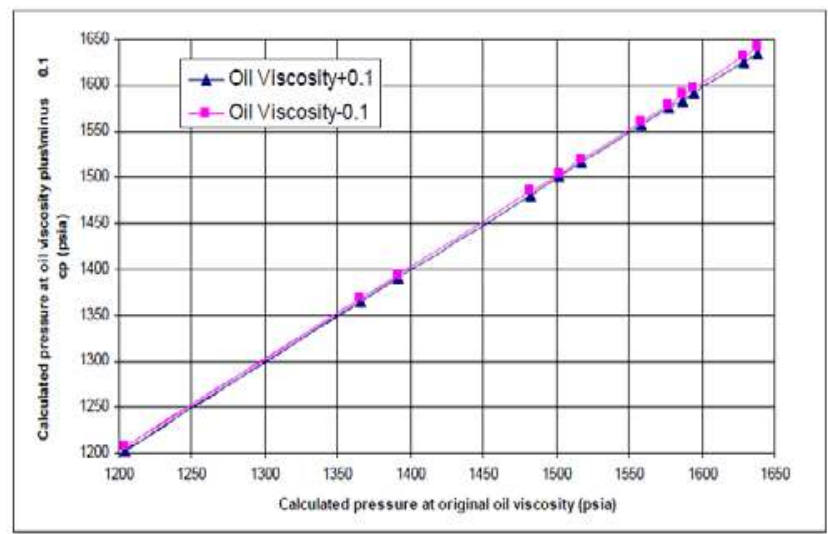

Fig. (15) Effect of oil viscosity on the pressure results using Modified Beggs and Brill Method.

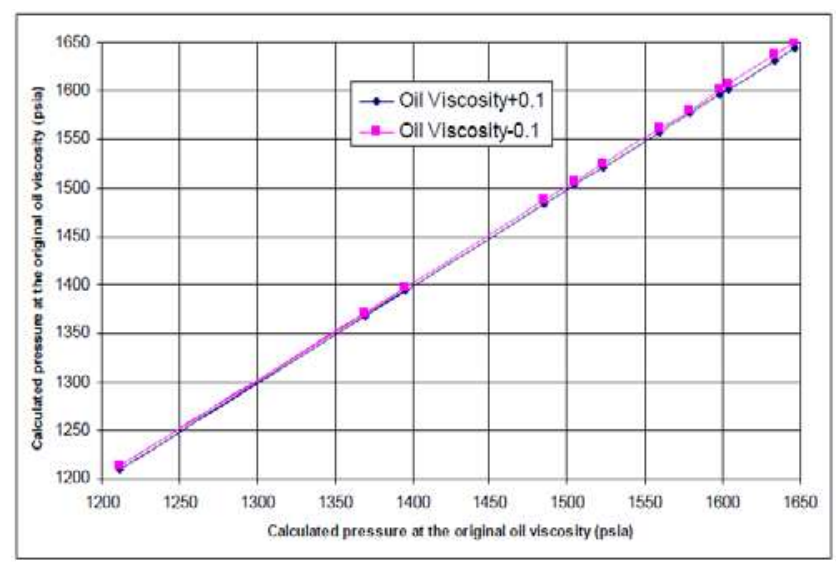

Fig. (16) Effect of oil viscosity on the pressure results using Aziz et al. Method. 


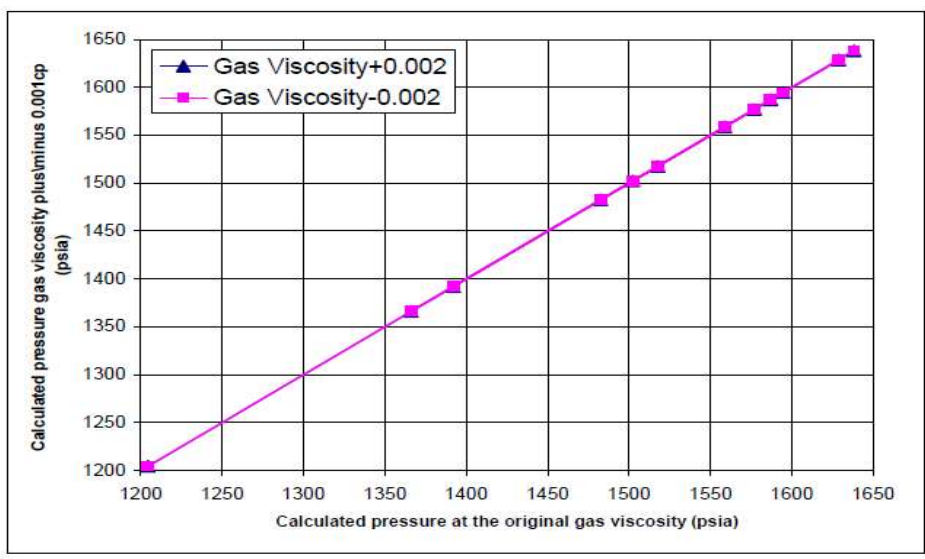

Fig. (17) Effect of gas viscosity on the pressure results using Modified Beggs and Brill Method.

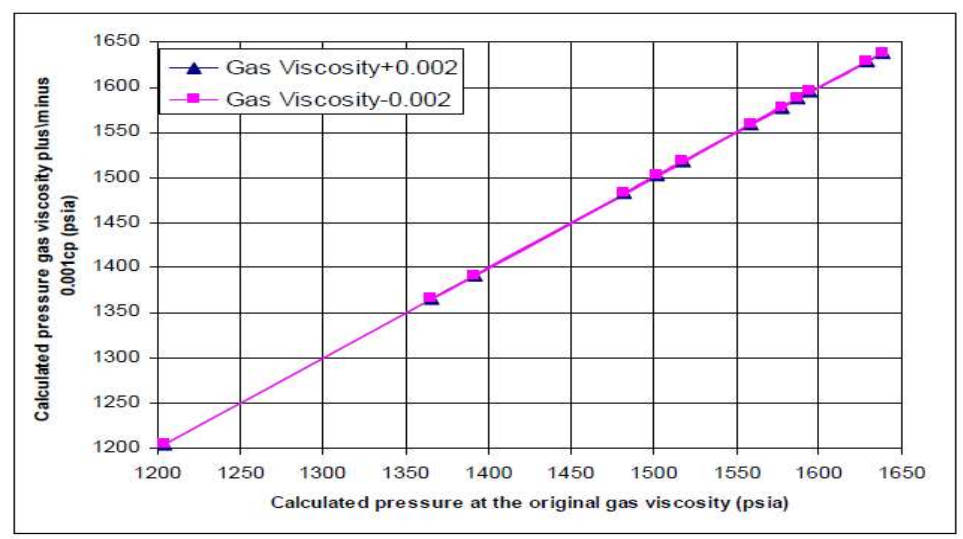

Fig. (18) Effect of gas viscosity on the pressure results using Aziz et al. Method.

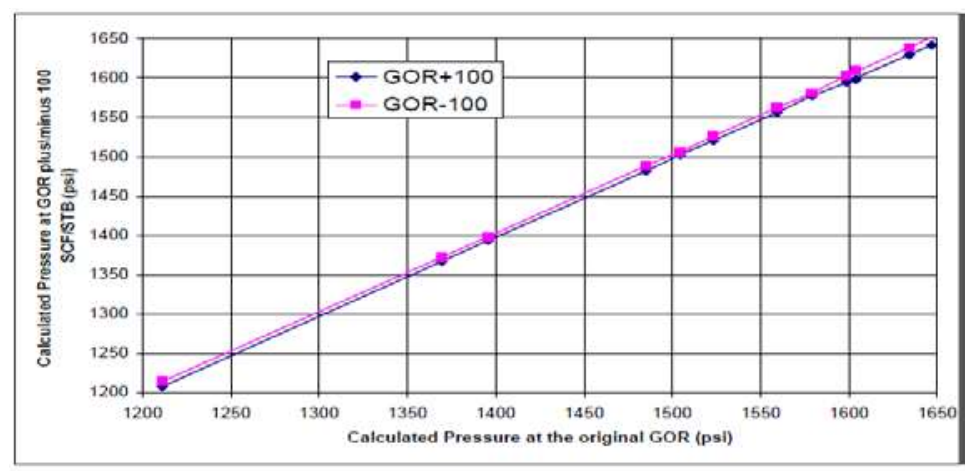

Fig. (19) Effect of gas-oil ratio on the pressure results using Modified Beggs and Brill Method. 


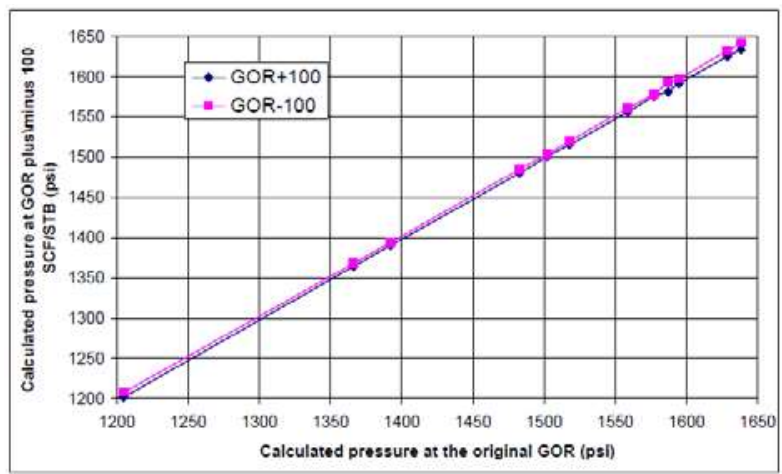

Fig. (20) Effect of gas-oil ratio on the pressure results using Aziz et al. Method.

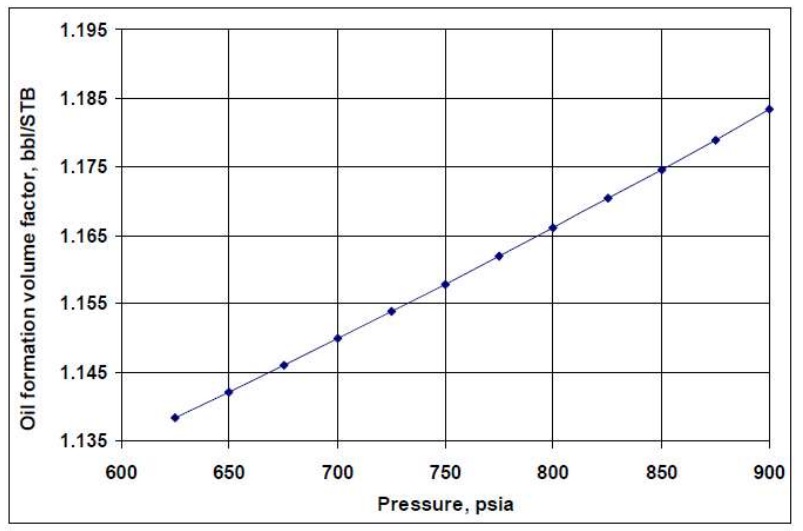

Fig. (21) The Effect of Pressure Change on the Oil Formation Volume Factor.

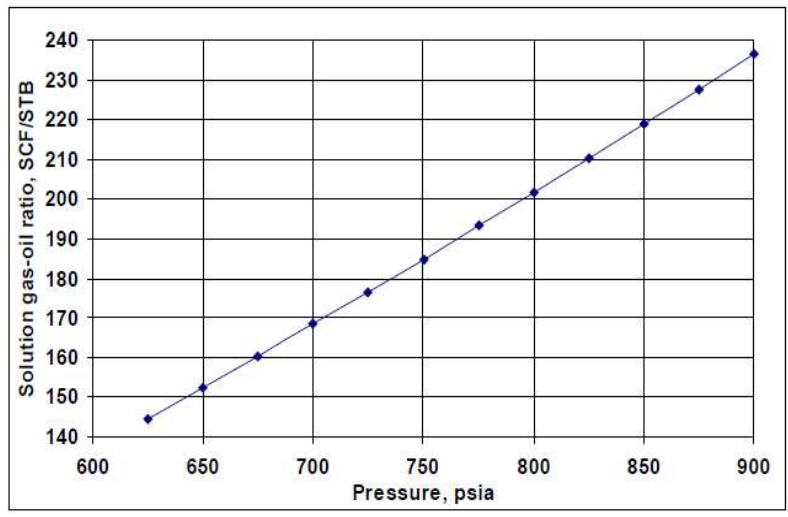

Fig. (22) The Effect of Pressure

Change on the Solution Gas-Oil

Ratio. 


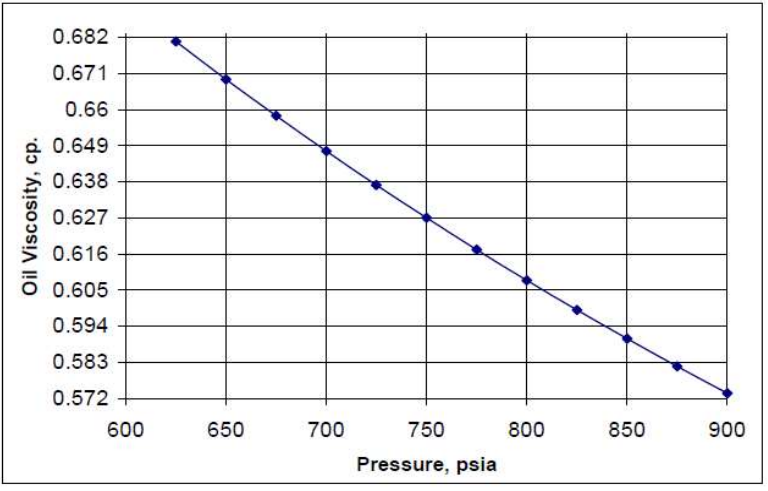

Fig. (23) The Effect of Pressure Change on the Oil Viscosity.

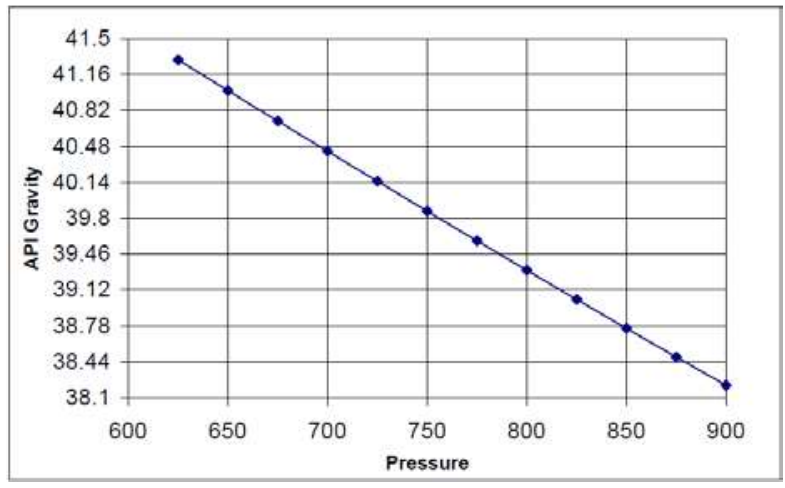

Fig. (24) The Effect of Pressure

Change on the API. 